\title{
Upaya Preventif Konflik Sosial dengan Pengembangan Materi Pembelajaran Berbasis Multikultural
}

\author{
Ida Bagus Sutresna1, I Putu Mas Dewantara ${ }^{2}$, Ade Asih Susiari Tantri ${ }^{3}$ \\ 1,2,3 Universitas Pendidikan Ganesha
}

Keywords:

learning materials;

Indonesian;

multicultural;

social conflict

\section{ABSTRAK}

Abstract: This research is a multi-year research that aims to develop multiculturalbased Indonesian language learning material as a preventive effort of social conflict. The development model used was ADDIE (Analysis-Design-DevelopmentImplementation-Evaluation). In the first year, the construction was carried out until the development stage. This research was done at the Ganesha University of Education (Undiksha) and Mahasaraswati University (Unmas) Denpasar with a sample of 10 lecturers (8 Undiksha lecturers and 2 Unmas lecturers). Data collection was carried out by two types of instruments, namely instruments for qualitative data collected by interview and observation techniques and instruments for quantitative data collected by questionnaire. The results showed that (1) need analysis of learning material showed the need for the development of multicultural based learning material as a preventive effort for social conflict, and (2) expert judgement results showed valid learning methods and received very good responses from lecturers (3.64) and very good from students (3.60).

\begin{abstract}
Abstrak: Penelitian ini adalah penelitian multiyears yang bertujuan untuk mengembangkan materi pembelajaran bahasa Indonesia berbasis multikultural sebagai upaya preventif konflik sosial. Model pengembangan yang digunakan adalah ADDIE (Analysis-Design-Development-Implementation-Evaluation). Di tahun pertama, pengambangan dilakukan sampaitahapan development. Penelitian ini berlokasi di Universitas Pendidikan Ganesha (Undiksha) dan Universitas Mahasaraswati (Unmas) Denpasar dengan sampel 10 dosen (8 dosen Undiksha dan 2 dosen Unmas). Pengumpulan data dilakukan dengan dua jenis instrumen, yaitu instrumen untuk data kualitatif yang dikumpulkan dengan teknik wawancara dan observasi serta instrumen untuk data kuantitatif yang dikumpulkan dengan angket. Hasil penelitian menunjukkan bahwa (1) Analisis kebutuhan materi pembelajaran menunjukkan perlunya pengembangan materi pembelajaran berbasis multikultural sebagai upaya preventif konflik sosial, dan (2) hasil uji ahli menunjukkan meteri pembelajaran valid dan memperoleh tanggapan sangat baik dari dosen $(3,64)$ dan sangat baik dari mahasiswa $(3,60)$.
\end{abstract}

Alamat Korespondensi:

E-mail: bagus.sutresna@undiksha.ac.id

\section{Pendahuluan}

Masyarakat Indonesia adalah masyarakat multikultural. Identitas masyarakat multikultural membawa makna hidupnya berbagai kebudayaan di dalamnya (Tilaar, 2004:29; Syaifuddin, 2006:6; Hidayatullah, 2012:76). Kemajemukan budaya merupakan aset yang tidak ternilai bagi bangsa ini. Namun, kemajemukan yang tidak ternilai tersebut akan menjadi beban bagi bangsa jika generasi muda Indonesia tidak diinternalisasi nilai kemajemukan budaya sejak dini. Potensi konflik sosial sangat besar apabila internalisasi nilai multikultural tidak berlangsung dengan baik. Konflik dapat dikatakan sebagai entitas yang potensial muncul dalam setiap perbedaan. Sebagai contoh adalah pembakaran pasar Glodok (peristiwa Mei Kelabu) di Jakarta tahun 1998, peristiwa Ambon-Maluku (pertarungan antara BugisButon-Makasar dan Ambon Islam melawan Kristen) tahun 1999-2002, peristiwa Sambas dan Palangkaraya (pertarungan Dayak, Melayu dan Tionghoa melawan Madura) tahun 1999, peristiwa 
separatisme Gerakan Aceh Merdeka (GAM), separatisme Organisasi Papua Merdeka (OPM), tawuran atau pertengkaran antarkelompok pelajar/mahasiswa, dan peristiwa lain yang bersifat konflik horizontal maupun vertikal.

Konflik yang bermuatan multikultural bahkan belakangan diangkat untuk tujuan politik tertentu. Cara-cara berkomunikasi dengan menggunakan demagogi-demagogi yang mengidentifikasi suatu kelompok lebih tinggi atau lebih mulia berdasarkan argumentasi keyakinan yang fundamental perlu dipahami agar tidak menjurus ke konflik sosial. Namun, demagogi-demagogi yang sektarian seperti ini tampaknya mudah mendapatkan massa karena rendahnya pemahaman multikultural kita dalam kehidupan berbangsa dan bernegara (Susongko, 2011). Di tayangan televisi kerap ditemukan kasus penolakan kepercayaan atau agama tertentu, kasus pembongkaran tempat suci atau lambang-lambang yang disucikan, patung-patung kepercayaan agama tertentu dirobohkan dengan alasan menyembah berhala, dan sebagainya.

Konflik yang muncul karena masalah kemajemukan ini sudah seharusnya mendapat perhatian lebih dari sekadar keprihatinan. Masuknya pendidikan multikultural pada pendidikan formal dan nonformal menjadi suatu yang urgen dilakukan. Pendidikan multikultural merupakan suatu cara yang tepat untuk membentuk manusia yang lebih demokratis, terbuka, dan toleran (Hanum, 2009:2; Priyatni dan Wahono, 2013:2). Paradigma multikultural secara implisit menjadi perhatian dari Pasal 4 UU No. 20 Tahun 2003 Sistem Pendidikan Nasional. Pasal tersebut menjelaskan, bahwa pendidikan diselenggarakan secara demokratis, tidak diskriminatif dengan menjunjung tinggi HAM, nilai keagamaan, nilai kultural dan kemajemukan bangsa. Namun, penekanan multikultural dalam pembelajaran selama ini tampaknya belum menunjukkan hasil yang maksimal. Kemampuan berpikir kritis menjadi penting, ketika kita harus hidup dalam masyarakat yang majemuk. Kemampuan berpikir ini akan membuat mahasiswa tidak dengan mudah melakukan penghinaan atau penilaian yang salah terhadap kelompok-kelompok yang tidak satu aliran dengan mereka (Fadhiila,dkk., 2016:75).

Berdasarkan penelitian yang dilakukan Basbay (dalam Fadhiila, dkk.,2016), penddikan multikultural secara langsung dapat membentuk peserta didik menjadi pribadi yang peduli, berpengetahuan, dan mempunyai kompetensi yang baik dalam menyelesaikan kesulitan-kesulitan yang dihadapi. Di perguruan tinggi, salah satu matakuliah yang menekankan pada pembentukan sikap dan kepribadian mahasiswa adalah matakuliah bahasa Indonesia yang masuk dalam kelompok matakuliah pengembangan keperibadian (MPK). Berdasarkan keputusan Dirjen Dikti No. 43/Dikti/Kep/2006 matakuliah bahasa Indonesia diharapkan mampu membentuk mahasiswa yang mampu berkomunikasi dengan baik, memiliki sikap rasa kebangsaan, dan cinta tanah air. Untuk mewujudkan tujuan tersebut, pemahaman tentang multikultural begitu diperlukan. Sangadji (2017:41) berpendapat bahwa penanaman pemahaman multikultural dapat dilakukan melalui pengintegrasian dalam berbagai matakuliah. Karena itu, salah satu cara menanamkan pemahaman multikultural adalah melalui materi pembelajaran. Fadhiila (2016) menyarankan agar materi pembelajaran yang dikembangkan dapat digunakan secara praktis dan mampu dengan efektif membangkitkan daya berpikir kritis mahasiswa menyikapi isu-isu yang berhubungan dengan multikultural.

Internalisasi pendidikan atau pemahaman multikultural dalam pembelajaran baik berupa pengembangan kurikulum, perangkat, materi ajar, maupun model pembelajaran pernah dilakukan oleh Masunah (2011), Chalimi (2011), Zuriah (2011), Andaryuni (2014), Julaiha (2014), Zain (2014), Sangadji (2016), Dewi dan Akhlis (2016). Kedelapan penelitian tersebut belum ada yang mengambil topik pengembangan materi pembelajaran bahasa Indonesia. Penelitian lain yang berada pada ranah pengembangan pembelajaran bahasa adalah penelitian Zulaeha (2013) mengambil topik pegembangan model pembelajaran keterampilan berbahasa Indonesia berkonteks multikultural di SMP. Kholik (2015) dengan topik pengembangan bahan ajar bahasa Indonesia berbasis pesantren multikultural. Bahan ajar yang dikembangkan adalah bahan ajar kelas VII semester ganjil. Fadhiila dkk. (2016) mengembangkan bahan ajar bermuatan pendidikan multikultural di tingkat SD kelas IV. Dari penelitian-penelitian tersebut dapat dilihat bahwa pengembangan materi pembelajaran bahasa Indonesia di perguruan tinggi berbasis multikultural belum pernah dilakukan. Di sinilah terletak kebaharuan penelitian ini dibandingkan dengan penelitian yang sudah ada sebelumnya.

Dalam keputusan Dirjen Dikti No. 43/Dikti/Kep/2006 disebutkan bahwa substansi kajian bahasa Indnesia di perguruan tinggi mencakup empat pokok kajian, yaitu (1) kedudukan bahasa Indonesia, (2) menulis, (3) membaca untuk menulis, dan (4) berbicara untuk keperluan akademik. Kajian pengembangan materi pembelajaran berbasis multikultural dilakukan pada bahan kajian kedudukan bahasa Indonesia. Substansi kajian ini dirasa paling tepat dan paling berpeluang besar untuk menginternalisasi nilai multikultural pada mahasiswa. Internalisasi nilai multikultural pada substansi ini akan menjadi dasar dalam penguasaan keterampilan berbahasa dengan berbagai tujuan. Untuk dapat 
menghasilkan produk pengembangan tersebut, dua masalah yang diangkat dalam penelitian ini adalah menyangkut kebutuhan pengembangan (studi pendahuluan) dan kevalidan produk yang dikembangkan.

\section{Metode}

Penelitian ini merupakan jenis penelitian dan pengembangan atau Research and Development (R\&D). Model pengambangan dalam pembelajaran melewati tiga tahap esensi pengembangan, yaitu pendahuluan, pengembangan, dan pengujian. Tiga esensi tahapan pengembangan tersebut dilaksanakan dengan bertumpu pada model pengembangan ADDIE (Analysis-Design-Development-ImplementationEvaluation). Penelitian ini berlokasi di Universitas Pendidikan Ganesha (Undiksha) dan Universitas Mahasaraswati (Unmas) Denpasar dengan sampel 10 kelas dan 10 dosen (8 dosen Undiksha dan 2 dosen Unmas). Pengumpulan data dilakukan dengan dua jenis instrumen, yaitu instrumen untuk data kualitatif yang dikumpulkan dengan teknik wawancara dan observasi serta instrumen untuk data kuantitatif yang dikumpulkan dengan angket.

\section{Hasil dan Pembahasan}

\section{1) Kebutuhan Materi Pembelajaran Bahasa Indonesia Berbasis Multikultural di Perguruan Tinggi}

Analisis pustaka terhadap dokumen-dokumen pendidikan menunjukkan bahwa pendidikan nasional Indonesia mempunyai visi mewujudkan sistem pendidikan sebagai pranata sosial yang kuat dan berwibawa untuk memberdayakan semua warga negaranya agar berkembang menjadi manusia yang berkualitas sehingga mereka proaktif menjawab tantangan zaman yang selalu berubah. Misi pendidikan adalah meningkatkan mutu pendidikan yang memiliki daya saing ditingkat nasional, regional, dan global serta meningkatkan keprofesionalan dan akuntabilitas lembaga pendidikan sebagai pusat pembudayaan ilmu pengetahuan, keterampilan, pengalaman, sikap, dan nilai berdasarkan standar yang bersifat nasional dan global (UU No. 20/2003). Visi dan misi tersebut menghasilkan rumusan reformasi pendidikan. Terkait dengan visi dan misi pendidikan nasional tersebut di atas, reformasi pendidikan meliputi hal-hal berikut.

Pertama, penyelenggaraan pendidikan dinyatakan sebagai suatu proses pembudayaan dan pemberdayaan peserta didik yang berlangsung sepanjang hayat, di mana dalam proses tersebut harus ada pendidik yang memberikan keteladanan dan mampu membangun kemauan, serta mengembangkan potensi dan kreativitas peserta didik. Prinsip tersebut menyebabkan adanya pergeseran paradigma proses pendidikan, dari paradigma pengajaran ke paradigma pembelajaran. Kedua, adanya perubahan pandangan tentang peran manusia dari paradigma manusia sebagai sumberdaya pembangunan, menjadi paradigma manusia sebagai subjek pembangunan secara utuh. Pendidikan harus mampu membentuk manusia seutuhnya yang digambarkan sebagai manusia yang memiliki karakteristik personal yang memahami dinamika psikososial dan lingkungan kulturalnya. Ketiga, adanya pandangan terhadap keberadaan peserta didik yang terintegrasi dengan lingkungan sosial-kulturalnya dan pada gilirannya akan menumbuhkan individu sebagai pribadi dan anggota masyarakat mandiri yang berbudaya. Keempat, dalam rangka mewujudkan visi dan menjalankan misi pendidikan nasional, diperlukan suatu acuan dasar (benchmark) oleh setiap penyelenggara dan satuan pendidikan, yang antara lain meliputi kriteria dan kriteria minimal berbagai aspek yang terkait dengan penyelenggaraan pendidikan. Dalam kaitan ini, kriteria dan kriteria penyelenggaraan pendidikan dijadikan pedoman untuk mewujudkan pendidikan yang berisi muatan yang seimbang dan holistik.

Reformasi pendidikan merupakan bentuk antisipasi menghadapi arus reformasi dan perubahan kehidupan dalam masyarakat yang mengglobal yang didasarkan pada "Empat Pilar Pendidikan" yang dicanangkan oleh UNESCO mulai tahun 1997 meliputi: (1) learning to know 'belajar untuk mengetahui', (2) learning to do 'belajar untuk melakukan', (3) learning to be 'belajar untuk menjadi seseorang', dan (4) learning to live together 'belajar untuk hidup bersama/bermasyarakat'. Empat pilar pendidikan dan empat reformasi pendidikan tersebut melandasi pentingnya konteks multikultural bagi peserta didik agar dalam kehidupan sehari-hari mereka dapat memahami dan berkomunikasi dengan orang tua, saudara, tetangga, teman, kenalan, orang asing; dengan yang lebih muda, sebaya, atau yang lebih tua; di rumah, di sekolah, atau di masyarakat; sama atau berbeda budaya tanpa mengalami kegagalan (communication breakdowns) yang menyebabkan timbulnya salah pengertian (misunderstandings).

Matakuliah Bahasa Indonesia adalah mata kuliah wajib yang dipelajari mahasiswa di semua jurusan atau program studi di seluruh fakultas di perguruan tinggi. Hal ini sebagaimana yang ditegaskan dalam UU nomor 2 tahun 1998 tentang Sistem Pendidikan Nasional yang ditegaskan kembali pada UU nomor 20 tahun 2003 tentang Sistem Pendidikan Nasional. Dalam SK Dirjen Dikti nomor 323/U/2000 
tentang Pedoman Penyususnan Kurikulum Pendidikan Tinggi dan Penilaian Hasil Belajar Mahasiswa, Bahasa Indonesia termasuk ke dalam Mata kuliah Pengembangan Keperibadian (MPK) bersama-sama dengan Pendidikan Agama dan Pendidikan Kewarganegaraan. Lebih lanjut SK Dirjen Dikti nomor 43/DIKTI/Kep/2006 tanggal 6 September 2006 tentang Rambu-rambu Pelaksanaan Kelompok Matakuliah Pengembangan Kepribadian menjelaskan bahwa kompetensi MPK Bahasa Indonesia adalah "menjadikan mahasiswa ilmuan dan profesional yang memiliki pengetahuan dan sikap positif terhadap bahasa Indonesia sebagai bahasa negara dan bahasa nasional dan mampu menggunakannya secara baik dan benar untuk mengungkapkan pemahaman, rasa kebangsaan, cinta tanah air, dan untuk berbagi keperluan dalam bidang ilmu, teknologi, dan seni serta profesinya masing-masing". Kompetensi tersebut jika dikaji lebih jauh mengarah pada perlunya pemahaman multikultural sehingga mampu menjunjung tinggi bahasa Indonesia sebagai bahasa nasional dan bahasa negara. Rasa kebangsaan dan cinta tanah air juga menuntut adanya pemahaman tentang keberagaman yang ada di Indonesia sehingga mampu memandang Indonesia secara utuh dalam konteks keberagaman.

Analisis yang selanjutnya dilakukan adalah analisis situasi yang menunjukkan bahwa Indonesia adalah bangsa yang majemuk. Kemajemukan ini terlihat dalam perbedaan bahasa, ras/etnik, budaya, dan agama. Kemajemukan di satu sisi adalah aset bangsa yang tidak ternilai harganya, namun di sisi lain kemajemukan dapat menjadi sumber pemicu konflik. Hal inilah yang perlu diwaspadai dan pendidikan dapat menjadi jalan upaya preventif konflik sosial. Pendidikan multikultural di perguruan tinggi merupakan respons terhadap perkembangan keberagaman popolasi di perguruan tinggi.

Analisis dokumen dan situasi menunjukkan bahwa diperlukan pendidikan multikultural di perguruan tinggi. Hal ini sejalan dengan hasil wawancara dengan dosen pengampu mata kuliah bahasa Indonesia di Undiksha dan Unmas Denpasar bahwa diperlukan pemahaman mengenai pendidikan multikultural. Alasan yang dikemukakan para dosen adalah (1) keberagaman yang ada di Indonesia, (2) Isu perpecahan bangsa akibat sikap egois kelompok mayoritas yang menyudutkan kelompok minoritas, (3) selama ini upaya memberikan pemahaman multikultural melalui himbaun masih perlu ditingkatkan terlebih karena melihat seringnya dipakai isu suku, agama, dan ras yang dipakai untuk memicu konflik, dan (4) keberagaman peserta didik yang ada.

Pertanyaan lain yang diajukan adalah terkait cara memberikan pemahaman multikultural di perguruan tinggi. Jawaban dosen mengarah kepada satu kesimpulan yaitu dengan mengintegrasikan pemahaman multikultural dalam materi pembelajaran. Diakui bahwa selama ini masih terbatas materi pembelajaran bahasa yang mengintegrasikan pendidikan multikultural. Dosen merasa bahwa keberadaan materi pembelajaran yang berbasis multikultural akan sangat membantu dosen dalam pembelajaran. Hasil penelitian ini sejalan dengan pendapat Arifudin (2007), Ibrahim (2008), Rosyada (2014), dan Suciantini (2017).

Pertanyaan selanjutnya yang diajukan adalah terkait fokus materi yang dikembangkan. Fokus materi yangdikembangkan merujuk pada SK Dirjen Dikti nomor 43/DIKTI/Kep/2006. Jawaban dosen terkait hal ini adalah bahwa pengintegrasian dapat dilakukan pada semua materi yang ada. Berdasarkan keempat cakupan materi yang ada, sebagian besar dosen menginginkan integrasi pendidikan multikulturan dilakukan pada subkajian kedudukan bahasa Indonesia. Alasan pemilihan subkajian ini adalah mengingat bahwa (1) subkajian ini adalah subkajian pertama dalam pembelajaran yang selama ini dilakukan, karena itu dipandang sangat baik, (2) memberikan penekanan tentang bahasa Indonesia sebagai bahasa negara dan bahasa nasional yang dalam perjuangannya tidak terlepas dari semangat keberagaman, dan (3) pada subkajian ini banyak kesempatan bagi dosen membicarakan tentang multikultural.

Selain wawancara dengan dosen, dilakukan juga wawancara dengan mahasiswa. Pertanyaan pertama yang diajukan adalah terkait keberagaman yang ada di mahasiswa. Jawaban mahasiswa adalah bahwa mereka melaksanakan kegiatan di kampus dalam keberagaman, baik dari suku, agama, maupun ras. Mahasiswa mengakui bahwa merasa bangga dengan keberagaman yang ada namun juga merasa waswas ketika masalah suku, agama, atau ras memiliki potensi memunculkan konflik. Hal ini berkaca dari pemberitaan yang ada terkait konflik suku, agama, maupun ras. Rahim (2017) berpendapat bahwa bagian tersulit dari pendidikan multikultural adalah penanaman sensitivitas atas keragaman budaya serta keadaan yang pluralis. Keberhasilan upaya preventif konflik sosial sangat ditentukan oleh hal ini.

Pertanyaan selanjutnya adalah mengenai perlu tidaknya pendidikan multikultural dalam pembelajaran bahasa Indonesia. Dari semua mahasiswa yang diwawancarai, semuanya menyatakan bahwa hal ini perlu dilakukan mengingat keberagaman yang ada dalam mahasiswa. Pertanyaan seanjutnya mengenai cara memasukkan pemahaman multikultural dalam pembelajaran. Jawaban mahasiswa ada yang menyatakan dapat diajarkan dengan integrasi dalam materi pembelajaran atau melalui berbagai metode yang diterampkan dalam pembelajaran. 
Hasil analisis pustaka dengan mengkaji dokumen-dokumen pendidikan dalam hubungannya dengan pembelajaran Indonesia dan hasil wawancara dengan dosen Undiksha dan Unmas Denpasar, serta mahasiswa menunjukkan bahwa diperlukannya materi pembelajaran yang berbasis multikultural. Materi pembelajaran yang menjadi fokus pengembangan adalah mengenai kedudukan bahasa Indonesia. Melalui pengembangan ini diharapkan mampu dijadikan alat preventif konflik sosial.

Berdasarkan hasil analisis yang telah dilakukan sebelumnya, pengembangan materi pembelajaran Bahasa Indonesia berbasis multikultural yakni sebagai upaya previntif konflik sosial, maka tujuan tersebutlah yang merupakan tujuan umum pengembangan materi pembelajaran. Adapun yang menjadi tujuan khusus dari pengembangan ini adalah terciptanya produk materi pembelajaran berbasis multikultural yang telah teruji.

\section{2) Pengembangan Materi Pembelajaran Berbasis Multikultural}

Materi pembelajaran yang telah dikembangkan diuji validasi dengan melibatkan dua orang ahli. Hasil validasi dari dua ahli tersebut dihitung dengan menggunakan formula Gregory. Tabulasi data menggunakan formula Gregory memberikan gambaran mengenai jumlah aspek yang disetujui dan tidak disetujui dari setiap aspek dalam model pembelajaran yang dikembangkan. Koefesien validasi minimal agar instrumen dan perangkat dapat dipakai dalam penelian adalah $\geq 0,7$. Setelah dilakukan perhitungan kedua pakar pada model pembelajaan diperoleh skor 1,0. Dengan demikian model pembelajaran yang dikembangkan dinyatakan valid. Selanjutnya untuk mengetahui kualitas model pembelajaran dari dosen dilakukan uji perorangan. Uji ini melibatkan 10 orang dosen dengan kreteria penilaian adalah sebagai berikut.

Hasil analisis menunjukkan bahwa dari penilaian 10 orang dosen dapat disimpulkan bahwa materi pembelajaran yang dikembangkan memiliki karakteristik sangat baik (dengan skor 3,64). Skor untuk tiap aspek dalam model pembelajaran juga berada dalam kategori sangat baik (skor berada dalam interval 3,50 $\leq \mathrm{Sr} \leq 4,0$ ). Jadi, dapat disimpulkan bahwa materi pembelajaran berbasis multikultural yang dikembangkan dalam matakuliah Bahasa Indonesia adalah valid dan sangat baik digunakan dalam pembelajaran.

Selain penilaian dari dosen, penilaian juga diberikan oleh mahasiswa terkait materi yang dikembangkan. Penilaian ini melibatkan 21 orang mahasiswa. Dari penilaian mahasiswa terhadap materi pembelajaran dilihat dari skor rata-rata, yaitu 3,60 adalah sangat baik. Kategori untuk tiap komponen terbagi dalam dua kategori, yaitu baik dan sangat baik. Dari hasil penilaian tersebut dapat disimpulkan bahwa materi pembelajaran sangat baik digunakan dan telah berbasis multikultural. Jika insersi ini berjalan baik maka pendapat Hikam (2018) terkait menjadikan pendidikan multikultural sebagai penangkal radikalisme ataupun harapan Munir (2018) untuk menjadikangenerasi penerus menjadi generasi beraklat baik sangat mungkin tercapai.

\section{Simpulan}

Simpulan dari temuan penelitian ini adalah (1) dibutuhkannya materi pembelajaran berbasis multikultural sebagai upaya preventif konflik sosial. Fokus materi yang dikembangkan adalah pada subkajian kedudukan bahasa Indonesia; dan (2) materi pembelajaran yang telah disusun dinyatakan valid oleh ahli. Sementara itu, penilaian dari dosen menunjukkan bahwa materi pembelajaran dinyatakan sangat baik dengan skor rata-rata 3,64. Hasil ini juga sejalan dengan penialaian yang dilakukan mahasiswa dengan skor rata-rata 3,60.

\section{Referensi}

Andaryuni, L. 2014. Pendidikan Multikultural Di Perguruan Tinggi. FENOMENA, Vol.6 No.1.

Arifudin, I. 2007. Urgensi implementasi pendidikan multikultural di sekolah. Insania, 12(2), 220-233.

Chalimi, I. R. 2011. Pengembangan Bahan Ajar dengan Pendekatan Multikultural Pokok Bahasan Perkembangan Masyarakat Indonesia pada Masa Reformasi untuk Siswa Kelas XII Program IPS SMA Negeri 3 Singkawang Kalimantan Barat. SKRIPSI Jurusan Sejarah-Fakultas Ilmu Sosial UM.

Departemen Pendidikan Nasional. 2003. Undang-Undang Nomor 20 Tahun 2003, Tentang Sistem Pendidikan Nasional, Jakarta: Depdiknas. 
Fadhiila, H. N.dkk. 2017. Pengembangan Bahan Ajar Berbasis Problem Based Learning Bermuatan Pendidikan Multikultural Untuk Mengembangkan Kemampuan Berpikir Kritis Siswa Kelas IV Sekolah Dasar. Journal of Primary Education, Vol.5, No.1, h.74-80.

Hanum, Farida. 2009. Pendidikan Multikultural sebagai Sarana Pembentuk Karakter Bangsa (Dalam Perspektif Sosiologi Pendidikan). Makalah disampaikan pada Seminar Regional DIY-Jateng dan Sekitarnya yang Diselenggarakan Himpunan Mahasiswa Pendidikan Sosiologi Universitas Negeri Yogyakarta, tanggal 14 Desember 2009.

Hidayatullah, A. 2012. Implementasi Pendidikan Multikultural dalam Praksis Pendidikan di Indonesia. Jurnal Pembangunan Pendidikan, Vol 1 No.1, h.72-82.

Hikam, M. A. (2018). Pendidikan Multikultural dalam Rangka Memperkuat Kewaspadaan Nasional Menghadapi Ancaman Radikalisme di Indonesia. Global: Jurnal Politik Internasional, 17(1), 1-17.

Ibrahim, R. 2008. Pendidikan Multikultural: Upaya Meminimalisir Konflik dalam Era Pluralitas Agama. EL TARBAWI, 1(1), 115-127.

Keputusan Direktorat Jenderal Pendidikan Tinggi Nomor 43/Dikti/Kep/2006 tentang RambuRambu Pelaksanaan Pembelajaran Kelompok Mata Kuliah Pengembangan Kepribadian di Perguruan Tinggi.

Munir, S. (2018). POLITIK PENDIDIKAN ISLAM BERBASIS MULTIKULTURAL: Konsep dan Strategi Pembelajaran Agama Islam dalam Mewujudkan Islam Rahmatan Li Al-'Ālamīn. Dirosat: Journal of Islamic Studies, 2(2), 149-182.

Priyatni, E. T., \& Wahono. 2013. Model Penyusunan Bahan Ajar Membaca Berbasis Pendidikan Multikultural dan E-Learning. Jurnal Litera, Vol 11 No.1

Rahim, R. 2017. Signifikansi pendidikan multikultural terhadap kelompok minoritas. Analisis: Jurnal Studi Keislaman, 12(1), 161-182.

Rosyada, D. 2014. Pendidikan Multikultural di Indonesia Sebuah Pandangan Konsepsional. SOSIODIDAKTIKA: Social Science Education Journal, Vol.1 No.1, h. 1-12.

Sangadji, K. 2017. Pendidikan Multikultural dalam Pengembangan Kurikulum Perguruan Tinggi (Sebuah Kajian Kurikulum). Biosel: Biology Science and Education, Vol.5, No.1.

Susongko, P. 2011. Pengembangan Standar Kompetensi Pada Pendidikan Multikultural di Sekolah. CAKRAWALA Jurnal Pendidikan, Vol 6, No.11.

Suciartini, N. N. A. 2017. Urgensi Pendidikan Toleransi dalam Wajah Pembelajaran sebagai Upaya Meningkatkan Kualitas Pendidikan. Jurnal Penjaminan Mutu, 3(1), 12-22.

Syaifuddin, A. F. 2006. Membumikan multikulturalisme di Indonesia. Jurnal Antropologi Sosial Budaya ETNOVISI, Vol.2, No.1, h.3-11.

Tilaar, H.A.R. 2004. Multikulturalisme, Tantangan-Tantangan Global Masa Depan dalam Transformasi Pendidikan Nasional. Jakarta: Gramedia Widiasarana Indonesia.

Zain, H. 2014. Pengembangan Pendidikan Islam Multikultural Berbasis Manajemen Sumber Daya Manusia. TADRIS: Jurnal Pendidikan Islam, Vol.8 No.1, h.108-124.

Zuriah, N. 2011. Model Pengembangan Pendidikan Kewarganegaraan Multikultural Berbasis Kearifan Lokal: Studi di Perguruan Tinggi Kota Malang (Doctoral dissertation, Universitas Pendidikan Indonesia) 